\title{
NUCLEAR AND INFRANUCLEAR LESIONS OF CRANIAL NERVES 3, 4, 6 AND THEIR CLINICORADIOLOGICAL CORRELATION
}

\author{
Viveka Saravanan $R^{1}$, Thamil Pavai $N^{2}$, Lakshmi Narasimhan $R^{3}$
}

${ }^{1}$ Senior Assistant Professor, Department of Neurology, Institute of Child Health, Madras Institute of Neurology, Madras Medical College. ${ }^{2}$ Senior Assistant Professor, Department of Neurology, Madras Institute of Neurology, Madras Medical College. 3 Director and Professor, Department of Neurology, Madras Institute of Neurology, Madras Medical College.

ABSTRACT
BACKGROUND
Palsies of any of the three cranial nerves supplying the extraocular muscles have their own presentations, disturbing ocular
motility.
The aim is to study the demography and clinicoradiological manifestations of patients with nuclear and infranuclear lesions of
cranial nerves 3,4 and 6.

\section{MATERIALS AND METHODS}

This was a descriptive study. We analysed nuclear and infranuclear lesions of cranial nerves 3, 4 and 6 of inpatients of Rajiv Gandhi Government General Hospital, Chennai after taking informed consent. X-ray skull, CT brain and MRI brain plain and contrast were done in all the patients, in the Department of Radiology in Rajiv Gandhi Government General Hospital, Chennai.

Inclusion Criteria- Patients with Nuclear and infranuclear lesions of cranial nerves 3, 4 and 6, who were inpatients in Rajiv Gandhi Government General Hospital, Chennai, between February 2011 to December 2013.

Exclusion Criteria- Patients with lesions of cranial nerves 3, 4 and 6 following head trauma were excluded from this study.

\section{RESULTS}

Out of the 40 patients studied, 15 had isolated unilateral $3^{\text {rd }}$, three had $4^{\text {th }}$, one had unilateral $6^{\text {th }}$ nerve palsy. 8 had combinations of cranial nerve palsy in the form of unilateral 3, 4, 6 nerves' involvement. Bilateral cranial nerves, 3, 4 and 6 involvement found in 2 patients (Squamous cell carcinoma of the nasopharynx, and aspergilloma). 8 patients had bilateral $6^{\text {th }}$ nerve palsy. 28 patients had abnormal MRI and 10 patients had abnormal CT findings.

\section{CONCLUSION}

Commonly affected was the $3^{\text {rd }}$, followed by $4^{\text {th }}$, and $6^{\text {th }}$ cranial nerve. Bilateral $6^{\text {th }}$ and unilateral $3,4,6$ were the commonest presentations, followed by bilateral 3, 4, 6 cranial nerves' involvement. MRI was abnormal in 70\% of the patients, whereas CT was abnormal only in $25 \%$ of patients. The commonest cause was Diabetes Mellitus, even in imaging negative patients.

\section{KEYWORDS}

Ocular Palsy, CT and MRI Brain, Diabetes.

HOW TO CITE THIS ARTICLE: Saravanan VR, Pavai TN, Narasimhan LR. Nuclear and infranuclear lesions of cranial nerves 3, 4, 6 and their clinicoradiological correlation. J. Evolution Med. Dent. Sci. 2017;6(94):6798-6802, DOI: 10.14260/jemds/2017/1472

\section{BACKGROUND}

Palsies of any of the three cranial nerves supplying the extraocular muscles have their own presentations, disturbing ocular motility. Abnormalities of ocular motility help in the localisation of lesions of the cerebral hemispheres, brainstem, cranial nerves (CNs), and even the striated muscle. Only one nerve may be involved or there may be a combination of the three nerves. The palsies are usually acquired.

Sometimes palsies can be congenital due to the developmental defect of the nucleus or motor nerve fibres. Oculomotor fibres can be interrupted intra-axially or extraaxially. Lesions can be in the foramen or extracranial e.g. intraorbital.

'Financial or Other Competing Interest': None.

Submission 23-10-2017, Peer Review 27-11-2017,

Acceptance 04-12-2017, Published 18-12-2017.

Corresponding Author:

Thamil Pavai $N$

Senior Assistant Professor,

Institute of Neurology,

Government Madras Medical College,

Government General Hospital, Chennai.

E-mail:arulpavai@gmail.com

DOI: $10.14260 /$ jemds/2017/1472

\section{(c) (i) $(\$)$}

All these Oculomotor nerves can be affected in the brainstem (nucleus or fascicular portion), in the subarachnoid space, in the cavernous sinus, at the superior orbital fissure, or in the orbit. ${ }^{1}$

MRI has become the most useful diagnostic tool in the localisation, diagnosis and management of the nuclear and infranuclear lesions of 3, 4, 6 cranial nerves.

In conditions like vasculitis and prothrombotic states, laboratory investigations add on to radiological findings and histopathological evaluation is useful when there are therapeutic difficulties.

3,4 and $6^{\text {th }}$ cranial nerve palsies can be due to head injury. In this study, we have excluded the head injury patients.

This study is about the clinicoradiological manifestations in nuclear, infranuclear lesions of 3, 4, $6^{\text {th }}$ cranial nerves.

\section{Aim of the Study}

To study the demography, the clinical localisations, the radiological findings, the various aetiological factors and clinicoradiological manifestations in patients with nuclear and infranuclear lesions of cranial nerves 3,4 and 6. 


\section{MATERIALS AND METHODS}

This was a descriptive study. In this study, we analysed data of patients with nuclear and infranuclear lesions of cranial nerves 3, 4 and 6, who were inpatients in Rajiv Gandhi Government General Hospital, Chennai between February 2011 to December 2013. Data pertaining to patient demographics, signs, investigations and radiological findings were analysed. Informed consent was taken for enrolment in the study and for the investigations. X-ray skull, CT brain plain and contrast (if necessary) and MRI brain plain and contrast study (if necessary) were done in all the patients, in the Department of Radiology in Rajiv Gandhi Government General Hospital, Chennai.

\section{Inclusion Criteria}

Patients with Nuclear and infranuclear lesions of cranial nerves 3, 4 and 6, who were inpatients in Rajiv Gandhi Government General Hospital, Chennai, between February 2011 to December 2013.

\section{Exclusion Criteria}

Patients with lesions of cranial nerves 3, 4 and 6 following head trauma were excluded from this study.

\section{Statistical Methods}

The descriptive data was analysed using SPSS version 16.0.

\section{RESULTS}

In this study, 40 patients were studied. Out of which 21 were female patients, 19 were male patients. (Fig. 1).

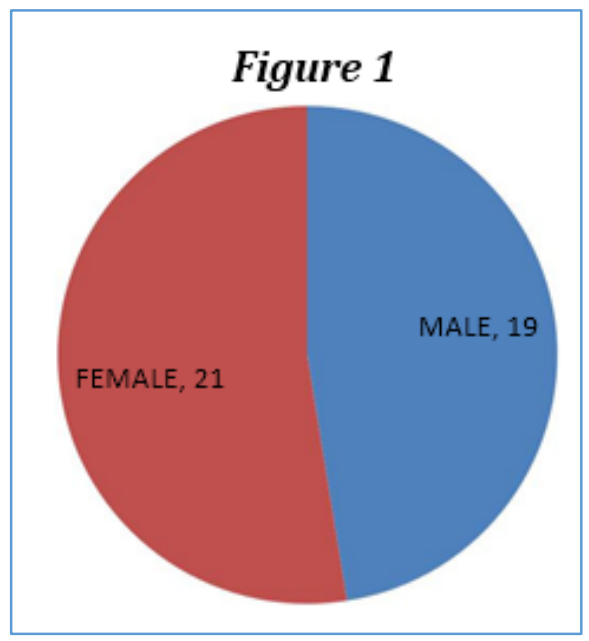

The average age of presentation in this study was 44.05 years. Out of 40 patients studied, 13 patients were in the age group of 30 to 40 years of age. (Table 1 ).

\begin{tabular}{|c|c|c|c|c|}
\hline \multirow{4}{*}{} & & \multicolumn{2}{|c|}{ Gender } & \\
\cline { 3 - 5 } & & Female & Male & Total \\
\hline \multirow{4}{*}{ Age Interval } & $20-30$ & 7 & 0 & 7 \\
\cline { 2 - 5 } & $31-40$ & 8 & 5 & 13 \\
\cline { 2 - 5 } & $41-50$ & 2 & 5 & 7 \\
\cline { 2 - 5 } & $51-60$ & 2 & 4 & 6 \\
\cline { 2 - 5 } & Above 60 & 2 & 5 & 7 \\
\hline & Total Count & $\mathbf{2 1}$ & $\mathbf{1 9}$ & $\mathbf{4 0}$ \\
\hline \multicolumn{4}{|c|}{ Table 1 } \\
\hline
\end{tabular}

In this study, 15 patients had unilateral $3^{\text {rd }}$ nerve palsy, 3 patients had unilateral $4^{\text {th }}$ nerve palsy and one patient had unilateral $6^{\text {th }}$ nerve palsy.

Out of the 40 patients, 15 patients had isolated unilateral $3^{\text {rd }}$ cranial nerve palsy. Out of the 15 patients, only one had incomplete $3^{\text {rd }}$ nerve palsy and rest of the 14 patients had complete $3^{\text {rd }}$ nerve palsy including pupillary fibres. In these 15 patients, 8 had diabetes, 3 had ophthalmoplegic migraine, 2 had PCOM artery aneurysm, one patient had caroticocavernous fistula and one patient had Claude's syndrome.

Only three patients had isolated $4^{\text {th }}$ nerve palsy. Among them various aetiologies were Midbrain stroke (1 patient), Multiple sclerosis ( 1 patient), and ophthalmoplegic migraine (1 patient).

Only one patient had unilateral $6^{\text {th }}$ nerve palsy, who was found to have tuberculous meningitis as aetiology.

8 patients had combinations of cranial nerve palsy in the form of unilateral 3, 4, 6 nerves' involvement. Among those, 3 patients had cavernous sinus thrombosis and 3 patients had Tolosa-Hunt syndrome. Lepra reaction was found in one patient and ophthalmoplegic migraine was found in one patient.

Bilateral cranial nerves 3, 4 and 6 involvement found in 2 patients (Squamous cell carcinoma of the nasopharynx in one patient and aspergilloma in one patient).

In this study, combination of either $3 \& 4,3 \& 6$ or $4 \& 6$ was not found.

In this study, 8 patients had bilateral $6^{\text {th }}$ nerve palsy. Among them, 6 patients had IIH and 2 patients had tuberculous meningitis. (Figure 2, Table 2).

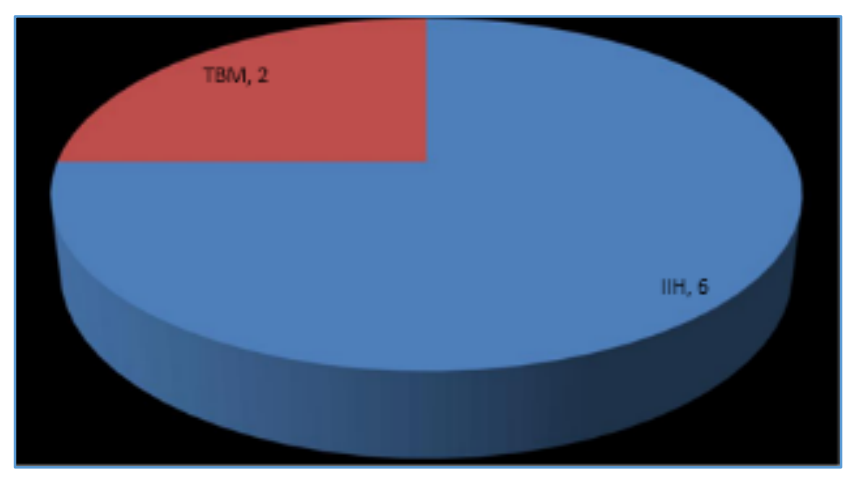

Figure 2

\begin{tabular}{|c|c|}
\hline Diagnosis & No. of Patients \\
\hline Idiopathic intracranial hypertension & 6 \\
\hline TB meningitis & 2 \\
\hline \multicolumn{2}{|c|}{ Table 2 } \\
\hline
\end{tabular}

In all these patients, clinical localisations were done. In 4 patients, the clinical localisations were done at the level of cavernous sinus. Among them one patient had Tolosa-Hunt syndrome rather than cavernous sinus involvement (confirmed by MRI).

Various common presentations in this study were: isolated $3^{\text {rd }}$ nerve palsy (15 patients), bilateral $6^{\text {th }}$ nerve palsy ( 8 patients) and unilateral 3, 4, 6 nerves' palsy (8 patients). (Figure. 3). 


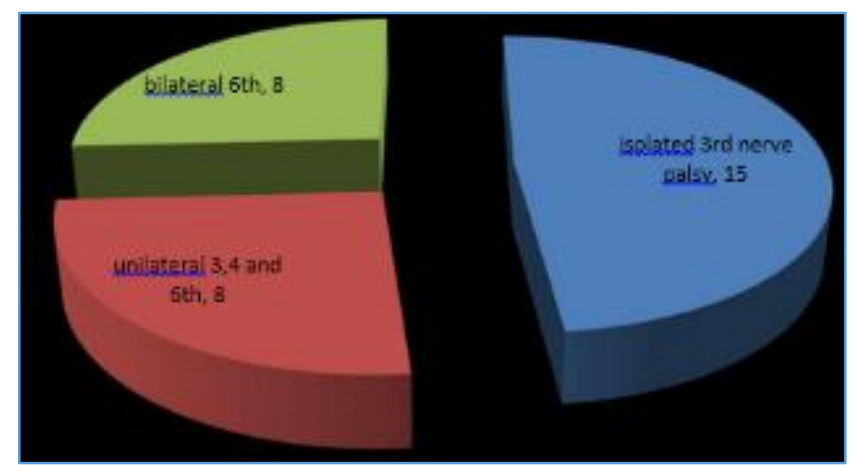

Figure 3

\begin{tabular}{|c|c|}
\hline Diagnosis & No. of Patients \\
\hline Squamous cell carcinoma & 1 \\
\hline $\begin{array}{c}\text { Bilateral cavernous sinus thrombosis due } \\
\text { aspergillosis }\end{array}$ & 1 \\
\hline \multicolumn{2}{|c|}{ Table 3. Bilateral Multiple Cranial Nerve Palsies } \\
\hline
\end{tabular}

All the 40 patients had undergone CT Brain. In those patients, 30 patients were having normal findings and rest of them were having abnormal findings. (Figure 4).

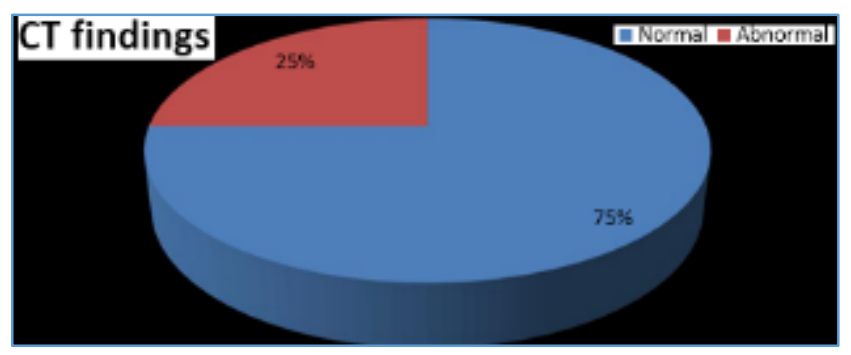

Figure-4

All the 40 patients had undergone MRI Brain (contrast if necessary). 28 patients had abnormal MRI findings, whereas 12 patients did not have any findings. All the patients who had abnormal CT Brain also had abnormal MRI Brain. In only one patient x-ray skull was abnormal who had bilateral 3,4, and $6^{\text {th }}$ cranial nerve involvement. (Table 4).

\begin{tabular}{|c|c|c|c|}
\hline \multirow{2}{*}{} & \multicolumn{2}{|c|}{ X-Ray Skull } & \\
\cline { 2 - 4 } & Abnormal & Normal & Total \\
\hline \multirow{2}{*}{ Bilateral Multiple } & 1 & 2 & 3 \\
\cline { 2 - 4 } Cranial Nerve Palsies & 1 & 39 & 40 \\
\cline { 2 - 4 } & $2.5 \%$ & $97.5 \%$ & $100.0 \%$ \\
\hline \multicolumn{3}{|c|}{ Table 4 } \\
\hline
\end{tabular}

In this study, 13 patients were already known diabetics. The duration of diabetes was as follows: $<10$ years- 1,10 to 15 years- 9 and $>15$ years- 3 . In 8 patients with diabetic third nerve palsy, 4 had duration of diabetes in the range of 6-13 years (in that 1 had partial $3^{\text {rd }}$ nerve palsy) and 4 had the duration in the range of $14-20$ years. (Table 5).

\begin{tabular}{|c|c|c|}
\hline \multirow{2}{*}{ Duration of DM } & \multicolumn{2}{|c|}{ Diabetic 3 $3^{\text {rd }}$ Nerve Palsy } \\
\cline { 2 - 3 } & Complete & Partial \\
\hline 0-5 years & 0 & 0 \\
\hline 6-13 years & 3 & 1 \\
\hline 14-20 years & 4 & 0 \\
\hline Total & 7 & 1 \\
\hline \multicolumn{2}{|c}{} \\
\hline
\end{tabular}

6 patients were known hypertensive cases in this study. Two patients presenting with isolated third nerve palsy had systemic hypertension. (Figure-6).

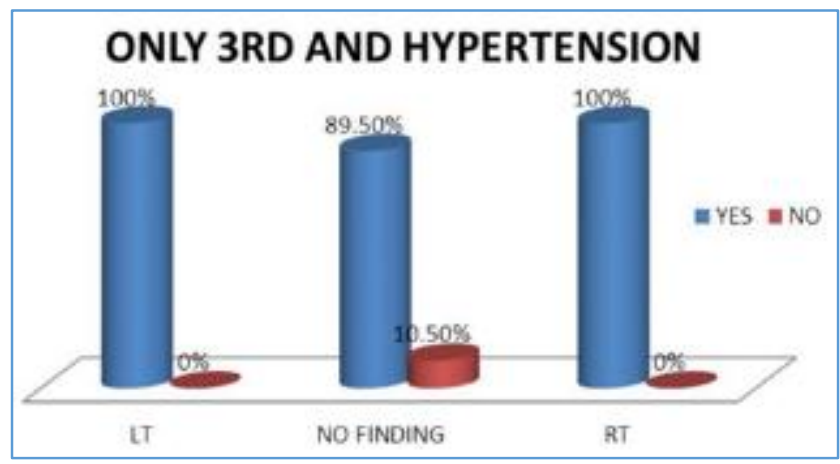

Figure 6

All the 4 patients who presented with the combination of 3,4 and 6 cranial nerves' palsy showed abnormalities in CT scan brain plain and contrast. 8 patients with bilateral $6^{\text {th }}$ nerve palsies were diabetic patients.

Skull X-ray abnormalities in bilateral multiple cranial nerve palsies were as follows:

Out of three patients with bilateral multiple cranial nerve palsies, 1 patient showed abnormality in skull X-ray.

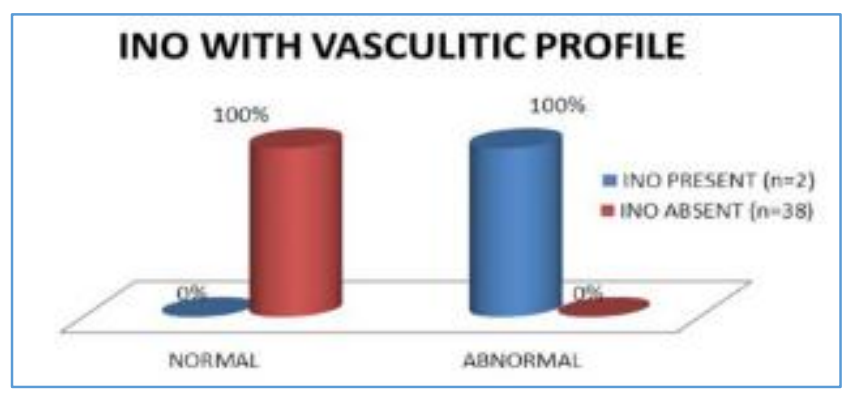

Figure 7

In both the patients with INO, the vasculitic profile was abnormal (Figure-7). Vasculitic profile was abnormal in 2 patients, with pontine infarcts.

\section{DISCUSSION}

In this study, 40 patients were included. 21 patients were female $(52.5 \%)$ and 19 patients were male (47.5\%). Hence, in this study of 3, 4, 6 cranial nerves, we had slight female preponderance.

Patients were in the age group ranging from 23 to 65 years. The average age is 44.05 years. 7 patients were in the age group of 20 to 30 years, 13 patients were in the age group of 31-40 years, 7 patients were in the age group of 41-50 years, 6 patients were in the age group of 51-60 years and 7 patients were in the age group of above 60 years. So, in this study, majority of patients are in the age group of 31-40 years. Out of 13 patients in this age group, 8 patients were female.

In this study, 15 patients were found to have isolated third nerve palsy (37.5\%). Compared to the study by Rucker et al, which showed $30 \%$ of patients with third nerve palsy, this study has a higher incidence $(37.5 \%)$. The commonest aetiology of isolated third nerve palsies is diabetes mellitus. 8 patients had diabetic third nerve palsy, followed by 
ophthalmoplegic migraine in 3 patients. 2 patients were having PCOM aneurysm, one patient had caroticocavernous fistula and one had Claude's syndrome. ${ }^{2}$ Among these, one patient of diabetic third nerve palsy had presented with partial 3rd nerve involvement (pupillary sparing). None of these patients had a nuclear lesion. In patients with diabetic third nerve palsy, 9 patients were male and six patients were female. The study conducted by Al Saleh et al in Arabic population, showed a male preponderance in patients with diabetic third nerve palsies and our study also has a similar picture. In 8 patients with diabetic third nerve palsy, the duration of diabetes in 8 patients was within the range of 6 13 years and in the remaining 4 patients the duration of diabetes was within the range of 14-20 years. In this study, 3 patients had isolated fourth nerve palsy (7.5\%). Compared to the study by Rucker et al which showed $11 \%$ of patients with isolated $4^{\text {th }}$ nerve palsy, this study has a lower incidence (7.5\%). None of these patients had diabetes as a risk factor. One patient had a midbrain infarct, one was a known case of relapsing remitting form of multiple sclerosis (In the previous episodes, she had only optic nerve involvement) and one was a case of ophthalmoplegic migraine. In a study conducted by Amy Gelfand et al in patients with ophthalmoplegic migraine, the involvement of isolated third cranial nerve was common $(83 \%)$ and involvement of isolated fourth cranial nerve was rare (2\%). ${ }^{3}$ In our study, out of 4 patients with ophthalmoplegic migraine, 3 had isolated $3^{\text {rd }}$ nerve palsy $(75 \%)$ and 1 had isolated $4^{\text {th }}$ nerve palsy (25\%). In this study, 9 patients had isolated sixth nerve palsy (22.5\%). Compared to the study by Rucker et al which showed $45 \%$ of patients with isolated $6^{\text {th }}$ nerve palsy, this study has a lower incidence. Out of these, one patient had unilateral sixth nerve palsy with TB meningitis as the aetiology. In the remaining 8 patients with bilateral $6^{\text {th }}$ nerve palsy, 7 patients were female and 1 patient was male, with a statistically significant $p$ value of 0.027. In the 8 patients with bilateral sixth nerve palsy, 6 patients had idiopathic intracranial hypertension and 2 patients had TB meningitis. The diagnosis of IIH was made with the clinical signs and after measurement of the CSF opening pressure. In this study, $27.5 \%$ patients had multiple cranial nerve palsy. Compared with the study by Rucker et al, which showed $14 \%$ of patients in this group, this study has a higher incidence. In this group, 8 patients had unilateral 3, 4 $\& 6^{\text {th }}$ cranial nerve involvement. 3 patients had cavernous sinus thrombosis, 3 patients had Tolosa-Hunt syndrome, 1 patient had a Lepra reaction and 1 patient had ophthalmoplegic migraine. Diabetes was the commonest aetiological factor in these patients (62.5\%) with unilateral 3, $4 \& 6^{\text {th }}$ cranial nerve lesions. 2 patients presented with bilateral $3,4 \& 6^{\text {th }}$ cranial nerve palsies. In those patients, one had squamous cell carcinoma of the nasopharynx with extension into the bilateral cavernous sinus and one patient with aspergillosis causing cavernous sinus thrombosis, who was diabetic. 2 patients presented with internuclear ophthalmoplegia. In both these patients vasculitic profiles were abnormal.

\section{Summarising, the common presentations in this study were-}

1. Isolated third nerve palsy in 15 patients.

2. Bilateral sixth nerve palsy in 8 patients.

3. Unilateral 3,4 and $6^{\text {th }}$ nerve palsy in 8 patients.
In this study, we did not have any patients with combination of $3 \& 4,4 \& 6$ or $3 \& 6$.

In this study, 13 patients were diabetics. The duration of diabetes was as follows: < 10 years -1 patient, 10-15 years -9 patients and $>15$ years -3 patients. 6 patients had systemic hypertension. Vasculitic profile was abnormal in 2 patients.

$\mathrm{X}$-ray skull was abnormal in 1 patient with squamous cell carcinoma. All the 40 patients were evaluated with CT scan brain plain and contrast. CT brain was abnormal in only 10 patients. 4 patients with cavernous sinus thrombosis, 2 patients with Tolosa-Hunt syndrome, 3 patients with TB meningitis and 1 patient with Lepra reaction had abnormal CT findings.

All the 40 patients were evaluated with MRI brain plain and contrast (if necessary). 28 patients had abnormal MRI findings, whereas 12 patients did not have any findings.

All the patients with abnormal CT brain also had abnormal MRI brain.

CT brain was normal in 6 patients with IIH, 4 cases with ophthalmoplegic migraine, 2 cases with Tolosa-Hunt syndrome, 2 patients with pontine infarct, 2 patients with multiple sclerosis, 2 patients with INO and in 1 patient with Claude's syndrome, but their MRI showed abnormalities.

In this study, MRI was found to be superior to CT scan brain in all patients with nuclear, brainstem, fascicular lesions and some patients with lesions in cavernous sinus and nerve lesions. ${ }^{4}$

In all the 8 patients with diabetic third nerve palsy, in 2 patients with PCOM aneurysm and in 2 patients with IIH, MRI was normal.

There was a correlation between the clinical findings, clinical localisation and imaging in 28 patients with MRI findings and in 2 patients with PCOM aneurysm, with CT angiogram findings. ${ }^{5}$

In a study by Pamela Y Blake et al with 50 patients of isolated third nerve palsy, 18 patients were with diabetic third nerve palsy and none of them showed MR changes and in among those who showed MRI changes, 2 had brainstem infarct, 2 had caroticocavernous aneurysm, 1 had ophthalmoplegic migraine and 1 had aneurysm. ${ }^{6}$

CT angiogram was done for 2 patients, in whom PCOM aneurysm was suspected, based on the clinical signs (headache with pupillary involvement), and both of them had aneurysm of PCOM.

Histopathological examination was done in 3 patients who had extensive lesion in MRI and not responding to therapy. 1 patient had Mucormycosis, 1 patient had aspergillosis and 1 patient had squamous cell carcinoma. Patients with Mucormycosis and aspergillosis were diabetics. ${ }^{7}$

Though INO is a common presentation in multiple sclerosis, in the two patients included in our study one had only isolated $3^{\text {rd }}$ and the other had isolated $4^{\text {th }}$ nerve palsy.

Chi SL et al suggested that diabetes mellitus or a combination of diabetes and hypertension, but not hypertension alone, is a risk factor for microvascular ischaemic ocular motor cranial neuropathies. In this study, we had 2 patients with both hypertension and diabetes as risk factors who developed $3^{\text {rd }}$ nerve palsies. 


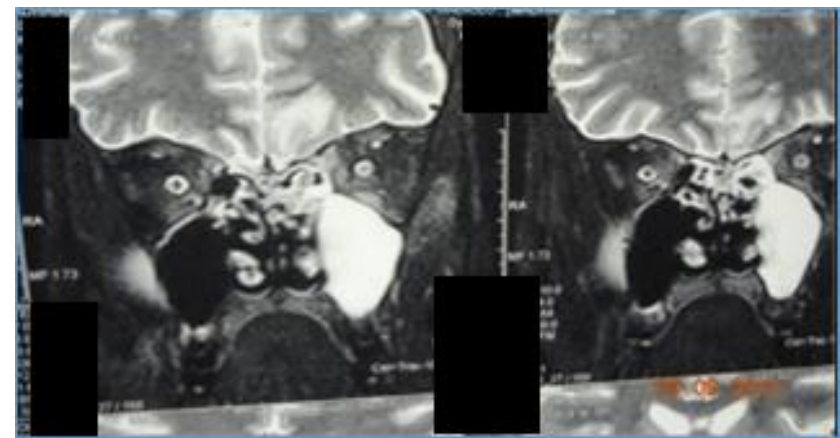

MRI of a Patient with Lepra Reaction showing Hyperintensities in Left Cavernous Sinus

\section{Limitations}

In this study, sample size was small because of short study period.

\section{CONCLUSION}

1. In this study, there was no sex preponderance.

2. Commonest age group of presentation was 30-40 years.

3. Among the cranial nerves 3,4 and 6 , commonly affected was the $3^{\text {rd }}$ cranial nerve followed by $4^{\text {th }}$ cranial nerve and $6^{\text {th }}$ cranial nerve.

4. Among the combinations of cranial nerves, bilateral $6^{\text {th }}$ nerve involvement and unilateral 3, 4, 6 cranial nerves' involvement were the commonest presentations, followed by bilateral $3,4,6^{\text {th }}$ cranial nerve involvement.

5. The combinations of $3 \& 4,3 \& 6$ and $4 \& 6$ cranial nerves' involvement were not found in our series.

6. MRI showed abnormal findings in $70 \%$ of the patients, whereas CT showed abnormal findings only in $25 \%$ of the patients.
7. The commonest cause of nuclear and infranuclear 3,4 , $6^{\text {th }}$ cranial nerve lesion was Diabetes Mellitus in this study.

8. The commonest cause of imaging negative aetiology in this study was Diabetes Mellitus.

\section{REFERENCES}

[1] Meienberg 0, Müri R. Nuclear and infranuclear disorders. Baillieres Clin Neurol 1992;1(2):417-34.

[2] Yousry I, Camelio S, Wiesmann M, et al. Detailed magnetic resonance imaging anatomy of the cisternal segment of the abducens nerve: Dorello's canal and neurovascular relationships and landmarks. J Neurosurg 1999;91(2):276-83.

[3] Chi SL, Bhatti MT. The diagnostic dilemma of neuroimaging in acute isolated sixth nerve palsy. Curr Opin Ophthalmol 2009;20(6):423-9.

[4] Miglio L, Feraco P, Tani G, et al. Computed tomography and magnetic resonance imaging findings in ophthalmoplegic migraine. Pediatr Neurol 2010;42(6):434-6.

[5] Chou KL, Galetta SL, Liu GT, et al. Acute ocular motor mononeuropathies: prospective study of the roles of neuroimaging and clinical assessment. J Neurol Sci 2004;219(1-2):35-9.

[6] Blake PY, Mark AS, Kattah J, et al. MR of oculomotor nerve palsy. Am J Neuroradiol 1995;16(8):1665-72.

[7] Rush JA, Younge BR. Paralysis of cranial nerves III, IV and VI. Cause and prognosis in 1000 cases. Arch Ophthalmol 1981;99(1):76-9. 